\title{
ELECTRIC MOTOR WINDING HEATING CONTROL
}

Key words: electric motor; heating control; stator winding; eyebolt socket; protective device.

\section{Authors' personal details}

1. Aleksey Nekrasov, ORCID: 0000-0001-6141-984X, Doctor of Technical Sciences, chief researcher of the laboratory of power supply and heat supply, Federal scientific engineering center «All-Russian Institute of mechanization», 109428, $1^{\text {st }}$ Veshnyakovsky proezd, 2, Moscow, Russia, e-mail: nalios@ mail.ru.

2. Anton Nekrasov, ORCID: 0000-0001-5816-8939, Candidate of Technical Sciences, Senior Researcher of the laboratory of power supply and heat supply, Federal scientific engineering center «All-Russian Institute of mechanization», 109428, $1^{\text {st }}$ Veshnyakovsky proezd, 2, Moscow, Russia, e-mail: nalios@ mail.ru.

The asynchronous motors reliability depends on the insulation state of their windings, which is due to the degree of heating during operation. The emergency operation of electric motors is accompanied by exceeding the permissible temperature of heating the windings. Specific protections, for several reasons, in many cases, do not protect the windings from such modes. Therefore up to $80 \%$ of motor failures in agriculture are due to burnout of the stator windings. The method for operational monitoring of heating and motor protection based on measuring and monitoring the temperature of the motor housing in the area of the eyebolt socket has been developed to improve the protection of the windings from emergency conditions. A quantitative relationship has been established between the actual heating temperature of the $T_{\text {wind }}$ winding and the heating temperature of the motor housing $\mathrm{T}_{\text {corp }}$ near the winding. There is no airflow in the eyebolt socket that affects the readings of the temperature sensor. The dependence of the temperature ratio is estab-

(С) Некрасов А.И., Некрасов А.А. lished, and the coefficient $\mathrm{C}_{\mathrm{t}}=\mathrm{C}_{\text {wind }} / \mathrm{C}_{\text {corp }}=$ $1,4 \ldots 1,7$ is determined. The measured value of the temperature of the motor housing $\mathrm{T}_{\text {corp }}$ is multiplied by the corresponding value of the $\mathrm{C}_{\mathrm{t}}$, and the actual values of the heating temperature of the frontal parts of the coil $\mathrm{C}_{\text {wind }}$ are obtained. The device, screwed into the eyebolt socket, is conveniently used for visual and sound control by maintenance personnel of the degree of heating of electric motors. Using the device with its shutdown effect may also be useful. Always available information about the temperature state of the stator windings of electric motors allows personnel to take timely necessary measures to eliminate emergencies and prevent premature motor failure. In agricultural production, the device is most suitable for monitoring relatively powerful electric motors involved in technological processes that do not allow sudden interruptions and are associated with loss of products and extensive material damage.

УДК 631.171:621.311

DOI: $10.31563 / 1684-7628-2020-55-3-112-119$

А.И. Некрасов, А.А. Некрасов

\section{ОЦЕНКА ТЕХНИЧЕСКОГО УЩЕРБА ОТ ОТКАЗОВ ЭЛЕКТРОДВИГАТЕЛЕЙ}

Ключевые слова: техническое обслуживание электрооборудования; отказы электродвигателей; технический ущерб; показатели эффективности; оборудование животноводческих ферм.

Введение. Совершенствование системы эксплуатации электрооборудования позволит увеличить срок службы электрооборудования, сократить материальные затраты на приобретение нового и ремонт отказавшего электрооборудо- вания, а также снизить возникающие технологические ущербы сельскохозяйственных предприятий. Отказ электродвигателя вызывает экономический ущерб, состоящий из технологической и технической составляющих, возникших 
от недовыпуска животноводческой продукции и от замены электродвигателя. За прошедшее время изменились организационная форма, структура и экономическая основа сельскохозяйственного производства, оснащение электрифицированной техникой и оборудованием сельхозпредприятий, фермерских и крестьянских хозяйств, выпуском новых видов электрооборудования, в том числе электродвигателей и магнитных пускателей. Издана новая Система машин и технологий для комплексной механизации и автоматизации сельскохозяйственного производства на период до 2020 года (в России). Оценка ущербов от отказов электрооборудования в животноводстве основывается на ранее проводимых работах по определению ущербов, наносимых сельскохозяйственному производству при отключении электроэнергии и при отказах электрооборудования [1-3].

Методическая основа исследования. При оценке ущербов необходим комплексный подход к решению общей задачи повышения эксплуатационной надежности сельских электроустановок на основе использования информации по ущербам от отказов электроприводов технологического оборудования. Для применения в работе электротехнических служб сельхозпредприятий необходим удобный для расчета способ оценки ущербов без использования малозначащих составляющих, содержащий современный справочный материал по электрооборудованию и сельхозпродукции, удобный в пользовании специалистами сельхозпредприятий. При отказе электродвигателя останавливается механизм или машина, на которой установлен данный двигатель, при этом возникающий ущерб в большей степени зависит от времени простоя рабочей машины. Большинство электродвигателей при выходе из строя не восстанавливают на месте, а отправляют на капитальный ремонт на специализированное предприятие, а на рабочую машину устанавливают резервный электродвигатель. При этом отказавший двигатель отправляют в ремонт не сразу, а при накапливании в хозяйстве до 10-15 штук для отправки на ремонтное предприятие, находящееся на значительном расстоянии от сельхозпроизводителя. На большинстве ремонтных предприятий обычно имеются обменные фонды, сокращающие время нахождения двигателей в ремонте. Ремонтное предприятие принимает неисправные двигатели и выдает отремонтированные в том же количестве, из числа которых в хозяйстве создают резервный фонд [4-7].
Ущерб от замены аварийно отказавшего электродвигателя состоит из затрат на демонтаж-монтаж и цены нового электродвигателя или стоимости его капитального ремонта. Также размер ущерба связан с мощностью, размерами и массой, конструкцией и способом установки на разных машинах, с различными условиями эксплуатации, включая удобство демонтажамонтажа. Поэтому однозначная оценка объема и условий работы электромонтеров с электродвигателем конкретного типа или мощности для расчетов на один аварийно отказавший электродвигатель невозможна. Также предполагается, что при современных условиях эксплуатации электродвигателей приблизительная средняя величина технической составляющей ущерба, обусловленной преждевременным ремонтом или списанием двигателя, может находиться в пределах половины его цены. Более точный технический ущерб от отказа электродвигателя может рассчитываться по-разному, в зависимости от этого заменяют отказавший на электродвигатель на новый или капитально отремонтированный с использованием исправных элементов, или электродвигатель подвергается ремонту на месте установки либо в электроцехе сельхозпредприятия. При этом учитывается остаточная стоимость электродвигателя и все другие расходы и отчисления, что значительно усложняет расчеты. Имеющаяся информация по номенклатуре поставляемых сельскому хозяйству электродвигателей показывает, что заводы-изготовители поставляют в основном двигатели общепромышленного исполнения, которые используются в условиях, на которые они не рассчитаны. При низком качестве капитального ремонта срок службы отремонтированных двигателей не превышает 1-1,5 лет [2].

В таблицах 1-4 представлена необходимая для расчета технической составляющей ущерба исходная информация по стоимости, массе, капитальному ремонту различных типов единых серий асинхронных двигателей (в России), наиболее применяемых в сельскохозяйственном производстве [5, 6].

Полученная информация по электродвигателям предназначена для использования при проведении экономической оценки ущербов от отказов электрооборудования, планировании мероприятий по техническому обслуживанию и повышению эксплуатационной надежности электрооборудования для обеспечения высокоэффективной работы оборудования животноводческих ферм. 
Таблица 1 Стоимость электродвигателей серии 5А при мощности, кВт

\begin{tabular}{|c|c|c|c|c|c|c|c|c|c|c|}
\hline \multirow{2}{*}{$\begin{array}{c}\text { Частота } \\
\text { вращения, мин }{ }^{-1}\end{array}$} & \multicolumn{10}{|c|}{ Стоимость электродвигателей, руб., при мощности в кВт } \\
\hline & 5,5 & 7,5 & 11 & 15 & 18,5 & 22 & 30 & 37 & 45 & 55 \\
\hline 3000 & - & - & 18070 & 27054 & 28594 & 32349 & 38799 & 59210 & 66912 & 80996 \\
\hline 1500 & - & 16045 & 19330 & 25802 & 29075 & 33408 & 43517 & 61135 & 69511 & 75673 \\
\hline 1000 & 17920 & 19611 & 25706 & 29075 & 36874 & 54492 & 62965 & 76828 & 97307 & 106089 \\
\hline 750 & 21951 & 26091 & 30423 & 38799 & 60269 & 65371 & 83856 & 101090 & 115291 & 132926 \\
\hline
\end{tabular}

Таблица 2 Масса электродвигателей 5А при мощности, кВт

\begin{tabular}{|c|c|c|c|c|c|c|c|c|c|c|}
\hline \multirow{2}{*}{$\begin{array}{c}\text { Частота } \\
\text { вращения, } \text { мин }^{-1}\end{array}$} & \multicolumn{10}{|c|}{ Масса электродвигателей, кг, при мощности, кВт } \\
\hline & 5,5 & 7,5 & 11 & 15 & 18,5 & 22 & 30 & 37 & 45 & 55 \\
\hline 3000 & - & - & 70 & 106 & 112 & 140 & 155 & 235 & 255 & 340 \\
\hline 1500 & - & 64 & 76 & 111 & 120 & 145 & 165 & 245 & 270 & 345 \\
\hline 1000 & 63 & 74 & 108 & 129 & 160 & 245 & 280 & 330 & 430 & 450 \\
\hline 750 & 74 & 108 & 124 & 160 & 240 & 260 & 340 & 430 & 460 & 705 \\
\hline
\end{tabular}

Таблица 3 Средняя стоимость электродвигателей АИР

\begin{tabular}{|c|c|c|c|c|c|c|c|c|c|c|c|c|}
\hline \multirow{2}{*}{$\begin{array}{c}\text { Частота } \\
\text { вращения, об/мин }\end{array}$} & \multicolumn{12}{|c|}{ Стоимость электродвигателей, руб., при мощности, кВт } \\
\hline & 0,25 & 0,55 & 1,1 & 2,2 & 3,0 & 4,0 & 5,5 & 7,5 & 11 & 18,5 & 22 & 30 \\
\hline 3000 & 2020 & 2508 & 3416 & 4666 & 5844 & 7174 & 8279 & 10484 & 15153 & 23593 & 31081 & 36038 \\
\hline 1500 & 2395 & 3198 & 4126 & 5647 & 7217 & 8074 & 10861 & 13682 & 16464 & 25613 & 31674 & 38617 \\
\hline 1000 & 2818 & 3542 & 4602 & 7102 & 10142 & 11028 & 14317 & 15670 & 23224 & 33950 & 41945 & 48045 \\
\hline 750 & 3670 & 5493 & 6850 & 10371 & 11433 & 15009 & 15998 & 23200 & 26039 & 43626 & 46525 & 60500 \\
\hline
\end{tabular}

Таблица 4 Масса электродвигателей АИР

\begin{tabular}{|c|c|c|c|c|c|c|c|c|c|c|c|c|}
\hline \multirow{2}{*}{$\begin{array}{c}\text { Частота } \\
\text { вращения, мин }{ }^{-1}\end{array}$} & \multicolumn{12}{|c|}{ Масса электродвигателей, кг, при мощности, кВт } \\
\hline & 0,25 & 0,55 & 1,1 & 2,2 & 3,0 & 4,0 & 5,5 & 7,5 & 11 & 18,5 & 22 & 30 \\
\hline 3000 & 3,8 & 6,1 & 9,2 & 15 & 30 & 26 & 32 & 48 & 78 & 130 & 150 & 170 \\
\hline 1500 & 4,2 & 8,1 & 9,4 & 18,1 & 35 & 29 & 45 & 70 & 84 & 140 & 160 & 180 \\
\hline 1000 & 5,6 & 9,9 & 16 & 27 & 43 & 48 & 69 & 82 & 125 & 160 & 195 & 255 \\
\hline 750 & - & 15,9 & 22 & 43 & 48 & 68 & 82 & 125 & 150 & 210 & 225 & 360 \\
\hline
\end{tabular}

Результаты и обсуждение. На основании многолетних исследований, проводимых лабораторией эксплуатации электрооборудования в сельском хозяйстве ВИЭСХ, установлено, что технический ущерб от отказа электродвигателя зависит от многих факторов, и точное его определение весьма затруднительно для практических расчетов в условиях сельхозпредприятий. Технический ущерб $\mathrm{y}_{\text {т, }}$ связанный с заменой отказавшего электродвигателя, состоит из затрат

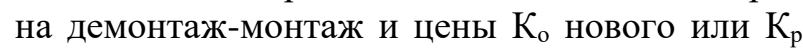
капитально отремонтированного электродвигателя с учетом выработанного ресурса. В общем виде техническая составляющая ущерба от преждевременного выхода из строя электродвигателя, не отработавшего свой нормативный срок, можно определить по выражению [2]:

$$
\mathrm{y}_{\mathrm{T}}=\mathrm{C}_{\mathrm{M}}+\mathrm{K}_{\mathrm{H}}\left(\mathbf{1}-\frac{\boldsymbol{t}_{\phi}}{\boldsymbol{T}_{\mathrm{cл}}}\right)-\mathrm{C}_{л},
$$

где $\mathrm{C}_{\mathrm{M}}$ - затраты, связанные с заменой отказавшего электродвигателя новым (монтаж, демонтаж); $\mathrm{K}_{\mathrm{H}}$ - стоимость отказавшего электродвига- теля; $\mathrm{C}_{л}$ - ликвидная (металлолом) стоимость отказавшего электродвигателя; $T_{\text {сл }}-$ нормативный срок службы электродвигателя; $t_{\phi}$ - фактический срок службы электродвигателя.

По фактическим срокам службы в расчетах следует использовать информацию, которая получена от сельхозпредприятий, эксплуатирующих электрооборудование в соответствии с требованиями системы ППРЭсх. Нормативный срок службы для электродвигателей, работающих в тяжелых условиях животноводства, -7 лет, ликвидная стоимость лома электродвигателей - 20 руб./кг $(0,35 \$)$, а затраты на монтаж $10 \%$ стоимости нового электродвигателя. Результаты расчета по выражению (1) величины технического ущерба при отказе электродвигателей, работающих в условиях животноводческих помещений, представлены в таблице 5. Зависимость величины технического ущерба от срока службы при отказе электродвигателей в животноводстве для $1-0,55$ кВт; $2-3,0$ кВт; 3 $-5,5$ кВт представлены на рисунке 1 . 
Таблица 5 Результаты расчета величины технического ущерба при отказе электродвигателей в животноводстве, руб.

\begin{tabular}{|c|c|c|c|c|c|c|c|}
\hline \multirow{2}{*}{ Электродвигатель } & \multicolumn{7}{|c|}{ Технический ущерб при сроке службы t$_{\phi}$ лет } \\
\cline { 2 - 9 } & 1 & 2 & 3 & 4 & 5 & 6 & 7 \\
\hline АИР 0,55 кВт & 2899 & 2442 & 1985 & 1528 & 1074 & 615 & - \\
\hline АИР 3,0 кВт & 6208 & 5177 & 4146 & 3115 & 2084 & 1053 & - \\
\hline АИР 5,5 кВт & 9495 & 7944 & 6392 & 4840 & 3289 & 1737 & - \\
\hline
\end{tabular}

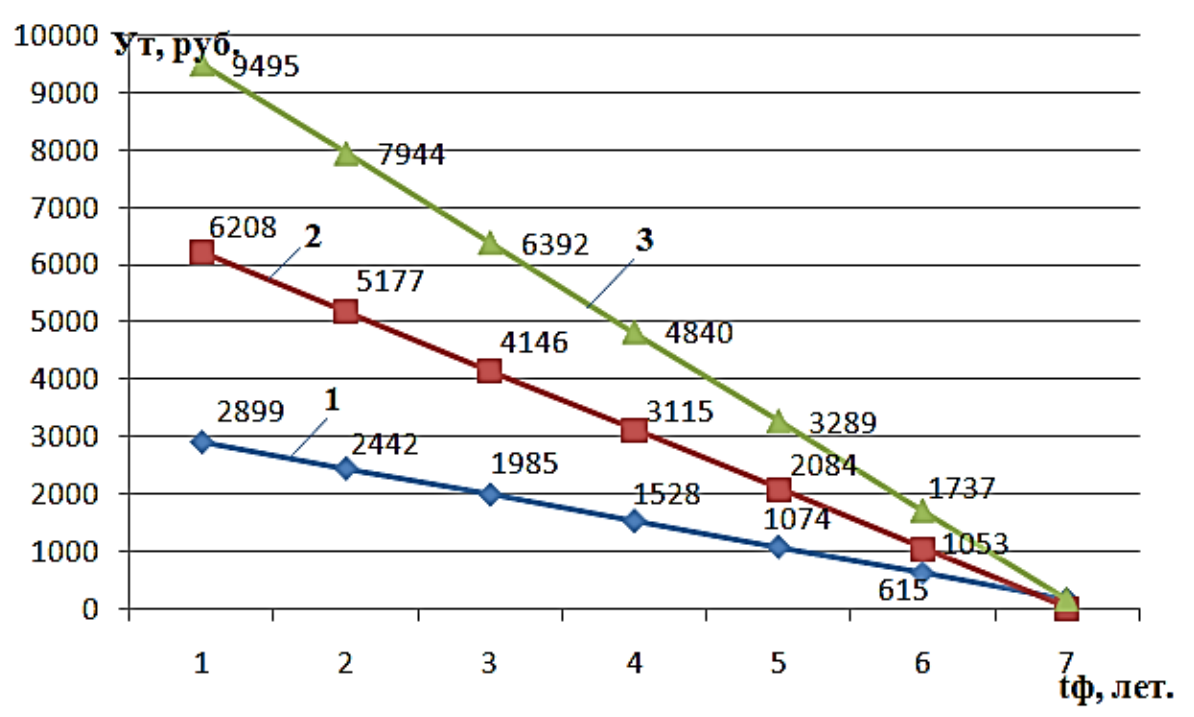

Рисунок 1

Зависимость величины технического ущерба от срока службы при отказе электродвигателей: $1-0,55$ кВт; $2-3,0$ кВт; $3-5,5$ кВт

При использовании электродвигателей в сельскохозяйственном производстве средний срок службы до первого капитального ремонта составляет в животноводстве 3-3,5 года, в растениеводстве - 4 года, на подсобных предприятиях - 5 лет [8-10]. Продолжительность ремонтного цикла между последующими капитальными ремонтами электродвигателей в среднем составляет: для животноводства 1,5 года, для растениеводства 2 года, для подсобных предприятий 2,5 года. Практика показывает, что электродвигатели должны ремонтироваться за весь срок службы не более одного раза. Уровень эксплуатации и качество ремонта необходимо повысить так, чтобы каждый двигатель служил до первого капитального ремонта не менее 5-6 лет, а после капитального ремонта - не менее 34 лет. Электродвигатели подлежат списанию по завершении нормативного срока службы, определяемого нормами амортизационных отчислений, по которым можно оценить число фактических капитальных ремонтов и средний технический ущерб. Для снижения величины материальных ущербов сельхозпредприятий от отказов путем снижения аварийности электродвигателей необходимо своевременное проведение упреждающих мероприятий по их техническому обслуживанию и ремонту с выполнением диагностических проверок технического состояния электродвигателей, обеспечение необходимого резерва запасных элементов и материалов для ремонтно-эксплуатационных нужд, применение соответствующих средств защиты электродвигателей от аварийных режимов, повышение оперативности и технической оснащенности электроремонтных бригад для выявления и устранения отказов.

На основании ранее выполненных исследований и расчетов следует, что более точное вычисление технической составляющей ущерба требует сбора достаточно большого объема информации, которую можно получить только в условиях практической эксплуатации электрооборудования сельхозпредприятия, имеющего укомплектованную энергетическую службу, выполняющую график проведения профилактических работ и аккуратно ведущую учетную эксплуатационную документацию. Необходимо также знать срок службы резервного электродвигателя с момента его выпуска заводом-изготовителем до момента установки на данной рабочей машине, срок службы отказавшего электродвигателя с момента выпуска заводом-изготовителем до отказа на данной рабочей машине, 
а также их нормативный срок службы. В процессе эксплуатации электродвигателя проводят ежегодные амортизационные отчисления от его первоначальной стоимости, которые со временем можно использовать для ремонта или замены новым изделием. Если отказавший электродвигатель не отработал нормативный срок до капитального ремонта или списания, предприятие при его ремонте или замене понесет убытки, входящие в состав технического ущерба У . Для удобства практической оценки технического ущерба целесообразным является использование обобщающего коэффициента ущерба ky, зависящего от фактического срока службы электродвигателя. При отказе электродвигателя со списанием и заменой на аналогичный возникаю-

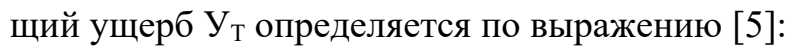

$$
\mathrm{y}_{\mathrm{T}}=\mathrm{K}_{\mathrm{M}} \cdot \mathrm{ky}_{\mathrm{y}}\left(\mathrm{t}_{\phi}\right)
$$

где $\mathrm{K}_{\mathrm{M}}$ - стоимость нового электродвигателя с монтажом, руб.; kу - коэффициент ущерба, о. е.; $\mathrm{t}_{\phi}-$ фактическое время службы электродвигателя, лет.

Зависимость коэффициента ущерба от фактического срока службы электродвигателя в жи- вотноводстве представлена на рисунке 2. Величина технического ущерба У строя электродвигателей, установленных на технологическом оборудовании животноводческих ферм, в зависимости от срока службы при нормативном сроке 7 лет [1] определяется умножением коэффициента ущерба на стоимость электродвигателя с монтажом. Как следует из рисунка 2, при среднем сроке службы электродвигателя в животноводстве 3-3,5 года коэффициент ущерба равен 0,5-0,6 о. е. Результаты расчета средней величины технического ущерба $\mathrm{У}_{\mathrm{T}}$ при Ку $=0,6$ от отказа электродвигателей АИР в зависимости от мощности, рассчитанного по выражению (2), представлены в таблице 6.

Предлагаемый метод определения технического ущерба позволяет при необходимости оперативно оценивать экономический ущерб изза преждевременных замен и капитальных ремонтов электродвигателей и другого электрооборудования, а также применим для оценочных расчетов при решении общих хозяйственных задач или при отсутствии конкретной исходной информации по отказам электродвигателей.

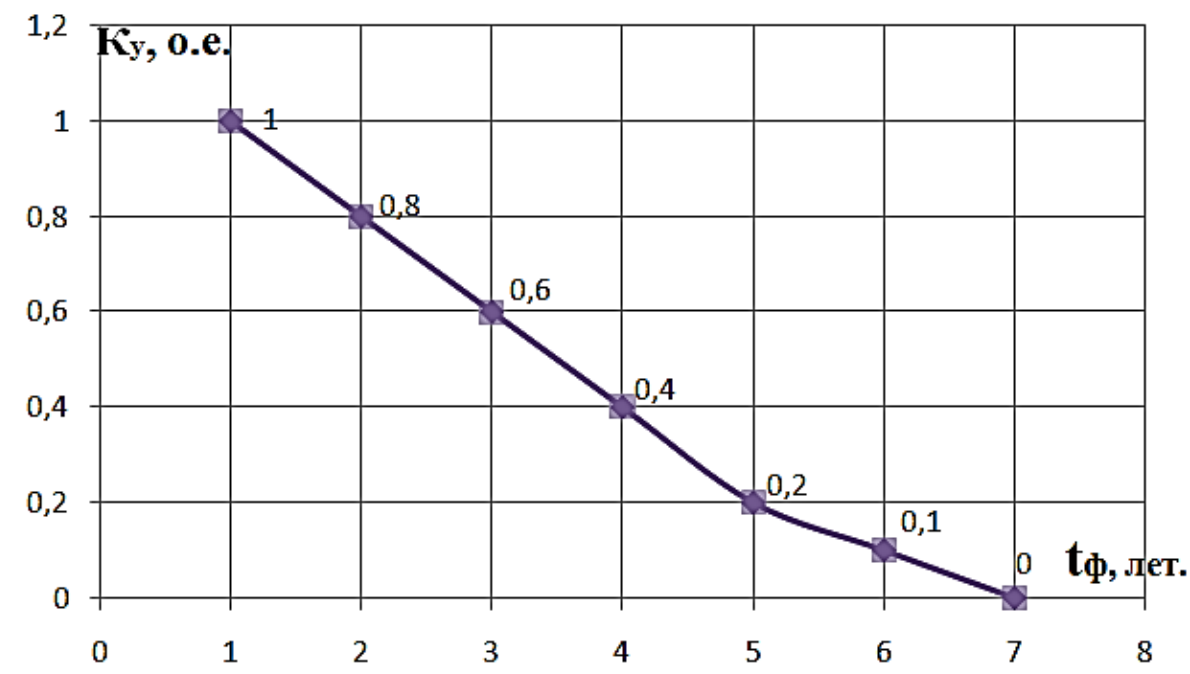

Рисунок 2

Зависимость коэффициента ущерба от фактического срока службы электродвигателя в животноводстве

Таблица 6 Результаты расчета технического ущерба от отказа электродвигателя АИР в животноводстве при $\mathrm{K}_{\mathrm{y}}=0,6$

\begin{tabular}{|l|c|c|c|c|c|c|}
\hline Мощность ЭД Р, кВт & 1,1 & 2,2 & 3,0 & 4,0 & 5,5 & 7,5 \\
\hline К $_{0}$ стоимость ЭД & 4126 & 5647 & 7218 & 8074 & 10861 & 13862 \\
\hline $\mathrm{C}_{\mathrm{M}}-$ стоимость монтажа & 413 & 565 & 722 & 807 & 1086 & 1386 \\
\hline $\mathrm{K}_{\mathrm{M}}=\mathrm{K}_{0}+\mathrm{C}_{\mathrm{M}}$ & 4539 & 6207 & 7940 & 8881 & 11947 & 15248 \\
\hline $\mathrm{У}_{\mathrm{T}}-$ величина ущерба & 2723 & 3724 & 4764 & 5328 & 7162 & 9149 \\
\hline
\end{tabular}

Выводы. Выполнена оценка технических составляющих ущербов от отказов электродвигателей технологического оборудования животноводческих ферм. Установлено, что величина технического ущерба от отказа электродвигателя зависит от многих факторов, учет которых усложняет расчеты, а результаты малозначительны для практического применения в усло- 
виях сельхозпредприятий. Основными составляющими технического ущерба являются фактический срок службы и неиспользованная стоимость электродвигателя. Для практического использования в производственных условиях животноводческих ферм средняя расчетная величина технического ущерба при аварийном отказе одного электродвигателя определяется с использованием усредненного коэффициента технического ущерба от стоимости нового электродвигателя с монтажом. Выполнены расчеты и построены зависимости величины технического ущерба от срока службы при отказе электродви- гателей различной мощности, используемых в животноводстве.

Результаты выполненной работы позволяют определять технический ущерб, связанный с отказами электродвигателей, определить степень экономической ответственности задействованного электрооборудования, уточнить и скорректировать периодичности проведения профилактических работ и ремонтов, выявить возможности совершенствования и повышения эффективности работы энергетической службы сельхозпредприятия.

\section{Библиографический список}

1. Система планово-предупредительного ремонта и технического обслуживания электрооборудования сельскохозяйственных предприятий [Текст]. М.: Агропромиздат, 1987. 187 с.

2. Сырых, Н.Н. Теоретические основы эксплуатации электрооборудования [Текст] / Н.Н. Сырых, Н.Е. Кабдин. М.: Агробизнесцентр, 2007. 514 c.

3. Strebkov D.S., Nekrasov A.I., Nekrasov A.A. Maintenance of power equipment system based on the methods of diagnosis and control of technical condition. Handbook of Research on Renewable Energy and Electric Resources for Sustainable Rural Development. January, 2018. Chapter 18. Pages: 535. pp. 421-448. DOI: 10.4018/978-15225-3867-7.

4. Nekrasov A.I., Nekrasov A.A. Method for definition of the required spare components set to maintain electric equipment for rural applications. International Russian Automation Conference (RusAutoCon). 2018. IEEE Xplore Digital library. P. 3.

5. Борисов, Ю.С. Методические рекомендации по прогнозированию и контролю технического состояния электродвигателей в сельскохозяйственном производстве [Текст] / Ю.С. Борисов, А.И. Некрасов, А.А. Некрасов. М.: ГНУ ВИЭСХ, 2011. $108 \mathrm{c}$.

6. Стоимость электродвигателей [Электронный ресурс]: заголовок с экрана. Режим доступа: http://electronpo.ru/price. Дата обращения: 24.02.2019.

7. Ерошенко, Г.П. Адаптация эксплуатации электрооборудования к особенностям сельскохозяйственного производства [Текст] / Г.П. Ерошенко, С.М. Бакиров. Саратов: Наука, 2011. $132 \mathrm{c}$.

8. Борисов, Ю.С. Фактические сроки службы электродвигателей в сельскохозяйственном производстве [Текст] / Ю.С. Борисов // Научно-тех- нический бюллетень по электрификации сельского хозяйства. Вып. 1(64). М.: ВИЭСХ, 1989.

9. Некрасов, А.И. Оценка остаточного ресурса электрооборудования по физическим характеристикам [Текст] / А.И. Некрасов, А.А. Некрасов. Вестник аграрной науки Дона. 2018. T. 1. № 41. C. 5-11.

10. Некрасов, А.И. Совершенствование системы технического сервиса электрооборудования сельхозпроизводителей [Текст] / А.И. Некрасов, Н.Н. Сырых, А.А. Некрасов. Международный научно-исследовательский журнал. 2016. № 9 (51). Часть 2. С. 73-75.

11. Пахомов, А.И. Технико-экономическая эффективность диагностического обслуживания электродвигателей в сельском хозяйстве [Текст] / А.И. Пахомов // Техника в сельском хозяйстве. 2012. № 5. C. 34-36.

12. Пахомов, А.И. Анализ методов диагностики изоляции асинхронных двигателей [Текст] / А.И. Пахомов // Техника в сельском хозяйстве. 2012. № 5. С. 15-17.

13. Пахомов, А.И. Эксплуатационная надежность асинхронных двигателей [Текст] / А.И. Пахомов, И.А. Переверзев, А.Ф. Кроневальд // Механизация и электрификация сельского хозяйства. 2008. № 3. С. 24-25.

14. Трушкин, В.А. Совершенствование методики оценки технологического ущерба от отказа электрооборудования в растениеводческих и тепличных комплексах [Текст] / В.А. Трушкин, А.В. Гузачев // Техника в сельском хозяйстве. 2012. № 1. С. 30-35.

15. Трушкин, В.А. Анализ перспективных стратегий ТО и Р электрооборудования сельскохозяйственного производства [Текст] / В.А. Трушкин, А.В. Гузачев // Актуальные проблемы энергетики АПК: материалы 7 международной научно-практической конференции; под общ. ред. В.А. Трушкина. 2016. С. 224-229. 
16. Левин, М.А. Анализ состояния технической эксплуатации электрооборудования сельскохозяйственных предприятий саратовской области [Текст] / М.А. Левин, Г.П. Ерошенко, В.А. Трушкин, А.С. Гузачев // Аграрный научный журнал. 2017. № 12. С. 70-72.
17. Пястолов, А.А. Эксплуатация и ремонт электроустановок [Текст] / А.А. Пястолов и др. М.: Колос, 1984. 271 с.

\section{Сведения об авторах}

1. Некрасов Алексей Иосифович, ORCID: 0000-0001-6141-984X, доктор технических наук, главный научный сотрудник лаборатории электроснабжения и теплообеспечения, Федеральное государственное бюджетное научное учреждение Федеральный научный агроинженерный центр «Всероссийский институт механизации» (ФГБНУ ФНАЦ ВИМ), 109428, г. Москва, 1-й Вешняковский проезд, 2, e-mail: nalios@mail.ru.

2. Некрасов Антон Алексеевич, ORCID: 0000-0001-5816-8939, кандидат технических наук, старший научный сотрудник лаборатории электроснабжения и теплообеспечения, Федеральное государственное бюджетное научное учреждение Федеральный научный агроинженерный центр «Всероссийский институт механизации» (ФГБНУ ФНАЦ ВИМ), 109428, г. Москва, 1-й Вешняковский проезд, 2, e-mail: nalios@mail.ru.

Аварийный отказ электродвигателя вызывает экономический ущерб, состоящий из технологической и технической составляющих, возникших от недовыпуска животноводческой продукции и от замены электродвигателя. Выполнена оценка технической составляющей экономического ущерба от отказов электродвигателей различной мощности, установленных для привода технологического оборудования в животноводстве. По результатам расчетов получены зависимости величины технического ущерба от стоимости и срока службы отказавшего электродвигателя. Отказы электродвигателей оборудования животноводческих ферм приводят к простоям технологических процессов и материальным ущербам. Размер ущербов возрастает в сельхозпредприятиях с большой удаленностью и разбросанностью молочных и откормочных ферм, что затрудняет своевременное устранение электромонтерами отказов электродвигателей и увеличивает продолжительность простоев. Определены основные факторы, влияющие на показатели эффективности использования электродвигателей в сельскохозяйственном производстве, обеспечивающие снижение интенсивности отказов и сокращение времени их устранения. Результаты выполненной работы позволяют определять техническую составляющую экономического ущерба, связанную с отказами электродвигателей, определить степень экономической ответственности задействованного электрооборудования, уточнить и скорректировать сроки проведения профилактических работ и ремонтов, выявить резервы улучшения эффективности работы энергетической службы сельхозпредприятия.

A. Nekrasov, A. Nekrasov

ASSESSMENT OF TECHNICAL DAMAGE FROM ELECTRIC MOTOR FAILURES

Key words: maintenance of electrical equipment; motor failures; technical damage; performance indicators; equipment for livestock farms.

\section{Authors' personal details}

1. Aleksey Nekrasov, ORCID: 0000-0001-6141-984X, Doctor of Technical Sciences, chief researcher of the laboratory power supply and heat supply, Federal scientific engineering center «All-Russian Institute of mechanization», 109428, $1^{\text {st }}$ Veshnyakovsky proezd, 2, Moscow, Russia, e-mail: nalios@ mail.ru.

2. Anton Nekrasov, ORCID: 0000-0001-5816-8939, Candidate of Technical Sciences, Senior Researcher of the laboratory power supply and heat supply, Federal scientific engineering center «All-Russian Institute of mechanization», 109428, $1^{\text {st }}$ Veshnyakovsky proezd, 2, Moscow, Russia, e-mail: nalios@ mail.ru. 
The emergency failure of the electric motor causes economic damage, consisting of the technological and technical components that arose from the shortage of livestock products and the replacement of the electric motor. The technical component of the economic damage from failures of electric motors of various capacities installed for the drive of technological equipment in animal husbandry has been evaluated. Based on the calculation results, the dependencies of the amount of technical damage on the cost and service life of a failed motor are obtained. Failures of electric motors of livestock farm equipment lead to technological downtime and material damage. The amount of damage is more significant in agricultural enterprises, with a large remoteness and dispersal of dairy and fattening farms,

(C) Некрасов А.И., Некрасов А.А. which complicates the timely repair of electric motor failures by electricians and increases the duration of downtime. The main factors that influence the performance indicators of electric motors in agricultural production, which reduce the failure rate and reduce the time to resolve them, are identified. The results of the work performed allow us to determine the technical component of the economic damage associated with the failure of electric motors. It also makes it possible to determine the degree of economic responsibility of the electrical equipment involved, clarify and adjust the timing of preventive maintenance and repairs, and identify the reserves for improving the efficiency of the energy service of the agricultural enterprise.

УДК 631.21

DOI: 10.31563/1684-7628-2020-55-3-119-126

Д.А. Соловьев, С.М. Бакиров, Г.Н. Камышова

РАЗРАБОТКА ЭЛЕКТРИЧЕСКОЙ СХЕМЫ

ЛОГИЧЕСКОГО УПРАВЛЕНИЯ ДВИЖЕНИЕМ СЕКЦИЙ ДОЖДЕВАЛЬНОЙ МАШИНЫ, ИСКЛЮЧАЮЩЕЙ ОДНОВРЕМЕННЫЙ ЗАПУСК ЭЛЕКТРОДВИГАТЕЛЕЙ

\section{Ключевые слова: электропривод; схема управления; дождевальная машина; энергозатраты; мощность электродвигателя.}

Введение. Движение электрифицированной дождевальной машины (ДМ) выполняется дискретно по секциям, согласно [1-4]. При включении электропривода опорной тележки крайней (последней) секции движение других опорных тележек секций подстраивается так, что при перемещении последующей опорной тележки секции от нормали более чем на угол $\varphi^{o}$ при длине трубопровода секции $l$ автоматически включается питание электропривода опорной тележки предыдущей секции (рисунок 1).

Имеется также прибор синхронизации движения в линию (ПСЛ) [5], принцип работы которого состоит в контроле угла $\varphi^{\circ}$ и включении/отключении питания электропривода. Такое дискретное управление приводит к случаям одновременного запуска нескольких электроприводов опорных тележек (до 3-10 секций) [6]. Тогда график нагрузочной характеристики источника в некотором промежутке времени имеет вид, представленный на рисунке 2. Для автономных источников питания, таких как переносной генератор с двигателем внутреннего сгорания на дизельном или бензиновом топ- ливе, данный режим приводит к тому, что требуется выполнение условия по выбору мощности источника:

$$
P_{\text {Hmax }}\left(t_{i}\right)>P_{\text {Hmax }}\left(t_{i}\right),
$$

где $P_{\text {Иmax }}\left(t_{i}\right)$ и $P_{\text {Hmax }}\left(t_{i}\right)$ - максимальные мощности соответственно источника электроэнергии и нагрузки в момент времени $t_{i}, \kappa B m$.

Выполнение условия (1) приводит к тому, что при выборе источника энергии требуется закладывать большую мощность, чтобы удовлетворять нагрузке в каждый момент ее действия, то есть с запасом. Вместе с этим сложение нагрузок секций приводит к совокупному показателю затрат энергии. Тогда, например, для переносного генератора обеспечение работы дождевальной машины (ДМ) сопровождается значительными потерями.

Перерасход горючего топлива очевиден, так как для требования нагрузки в конкретный момент времени, например, $1 \kappa B m$ * $ч$ электроэнергии, дизельный или любой другой (на горючем топливе) переносной генератор мощностью $10 \kappa B A$ будет сжигать топливо, обеспечивая около $10 \%$ мощности. В этом случае загрузка 